\title{
Patents on Tomatoes and Broccoli: Legal Positivists at Work
}

\author{
Axel Metzger
}

Published online: 28 June 2016

(C) Max Planck Institute for Innovation and Competition, Munich 2016

The EPO Enlarged Board of Appeal's decisions "Tomatoes II/Broccoli II" ${ }^{1}$ have received much attention by industries, NGOs and political actors. The patents in suit, EP 1211926 (the "tomato" patent) and EP 1069819 (the "broccoli" patent), are examples of a new type of patent on innovative plants resulting from classical breeding methods, so-called "native traits". These plants are of particular interest for the seed industry and the agricultural sector since genetically modified plants are strictly regulated in the European Union and, even more important, are not accepted by consumers. It is therefore not surprising that seed companies have rediscovered the appeal of breeding methods which abstain from genetic recombination but use techniques based on crossing and selecting, refined by genetic analysis. It is also not surprising that seed companies seek to protect their investments by patents. Yet, patents on food plants raise sensitive political and legal issues. NGOs fear that a further monopolization of food plants may endanger biodiversity and food production in the periphery, especially in the global south. Among lawyers, the discussion has mainly focussed on the interpretation of Art. 53(b) of the European Patent Convention, which excludes "plant or animal varieties or essentially biological processes for the production of plants or animals" from patentability. The critical questions here are whether this exception covers only "plant varieties" and "essentially biological processes" strictu sensu or whether the exception should be applied to all plant materials resulting from essentially biological processes. The patents in suit did not claim specific tomato or broccoli varieties but were broader in scope and covered all tomato and all broccoli plants possessing the described native trait.

${ }^{1}$ EPO Enlarged Board of Appeal, 25 March 2015, G 2/12 and G 2/13, OJ EPO 2016, A27 and A28.

\footnotetext{
A. Metzger $(\bowtie)$

Professor of Civil and Intellectual Property Law

Humboldt-University, Berlin, Germany

e-mail: metzger@rewi.hu-berlin.de
} 
These questions of interpretation of the EPC have now been decided by the Enlarged Board of Appeal: product claims on plants which are not restricted to specific varieties are not covered by Art. 53(b) EPC and may therefore be patentable subject matter. Reading the decisions "Tomatoes II/Broccoli II", one cannot blame the Board for having taken a decision without sufficient consideration. The reasons given for the decisions highlight all criteria one would expect from a classical interpretation of an international convention like the EPC. Still, the decisions give the impression of a legal positivists view on the development of European patent law on plants. The Board avoids any discussion of the economic and social effects of granting patents on native traits, even when it discusses the "need for secondary considerations". Also, the consequences for small and medium-sized enterprises in the breeding industry, which traditionally protect their innovations by plant variety rights and which have shown in the past that they are very innovative and highly competitive on the international markets, are not taken into account. Instead: "It has to be borne in mind that the role of the Enlarged Board of Appeal is to interpret the EPC using generally accepted principles of interpretation of international treaties. It is not mandated to engage in legislative policy." One may take this characterisation as an expression of judicial self-restraint. Yet, in an institutional setting where the "legislator" is an international organisation with 38 member states, it sounds like a truism to refer to the legislator, once the things are getting hot. Indeed, some European legislators - namely Germany and the Netherlands - have already reacted and implemented broader exclusions from patentability into their national patent acts. The European Union is currently considering whether the Directive 98/44 on the legal protection of biotechnological inventions should be amended or whether at least Council and Commission should publish a statement on the interpretation of the relevant provisions. But even if the European Union would get active and would exclude plants resulting from essentially biological processes altogether, it is hardly predictable whether EPO will follow this approach once the Enlarged Board of Appeal has taken such a clear stance.

For the time being, breeders, seed companies, farmers and the broader public must live with the patents granted by EPO. One may therefore expect that the scope of protection of this new type of patent claim will remain under focus in the coming years. The scope of protection above all depends on the drafting of the patent claims. In its current practice, the EPO examining division seems to abstain from granting patents based on mere phenotypic descriptions, as apparently accepted in the "Tomatoes II" decision by the Enlarged Board of Appeal. The trend is rather to grant product-by-process claims that describe a small number of phenotypic traits and specify the protected plants by reference to the genetic material used for the breeding or production. Whenever the genetic material is specified in the claim, Art. 8 of Directive 98/44 should be used to narrow the scope of protection to material derived from the material specified in the patent claim. Another approach to mitigate the effects of patents on native traits could be to lower the bar for compulsory licenses under Art. 12 of Directive 98/44. At the end, such an approach would fit into the larger picture of the current development of intellectual property law. Once the floodgate has been opened, only an adjustment of the scope of protection and the remedies may re-establish the balance of interest. 